\title{
Los modelos del pasado en los escritos retóricos de Cicerón: un estudio sobre su valor moral y formativo ${ }^{1}$
}

\section{[Models of the Past in Cicero's Rhetorical Writings: A Study about their Moral and Educational Value]}

\author{
FRANCISCO J. BELLIDO \\ Universidad de Málaga \\ Departamento de Filosofía \\ España \\ franciscojavbellido@uma.es
}

\begin{abstract}
Resumen: Defiendo que lo novedoso de la concepción de Cicerón de los modelos basados en personajes del pasado consistió en conferirles habilidades que podían aplicarse a las disputas legales y políticas de Roma y, al mismo tiempo, mejorar el desempeño de los oradores jóvenes y aprendices mediante un modelo mixto de retórica. La destreza técnica y la prudencia práctica de estas autoridades para advertir aspectos cruciales en casos particulares y adaptarse a circunstancias adversas sirven como ejemplos para los oficios del rétor y del abogado. Esas dos características, y no el amplio conocimiento o la fama que estos personajes alcanzaron, llevaron a Cicerón a reconocer a ciertos oradores y pensadores como fuentes de inspiración moral y formativa. Palabras clave: autoridades del pasado; retórica romana; decorum; educación moral
\end{abstract}

\begin{abstract}
I argue that Cicero's innovative understanding of the models based on characters from the past consisted in conferring them skills to be applied in the legal and political disputes of Rome and, at the same time, to improve the performance of young orators and apprentices with a mixed model of rhetoric. Both the technical ability and practical prudence of these authorities to see crucial aspects in particular cases and to adapt to adverse circumstances serve to the craft of rhetoricians and lawyers. These two features, and not the large knowledge or fame these figures acquired in life, took Cicero to recognise certain orators and thinkers as sources of moral and formative inspiration
\end{abstract}

Keywords: authorities from the past; Roman rhetoric; decorum; moral education

${ }^{1}$ Este artículo ha sido posible gracias a la beca de Formación de Profesorado Universitario (FPU) financiada por el Ministerio de Educación de España. Asimismo, se escribió en el marco del proyecto de investigación "Civic Constellation III: Democracy, Constitutionalism and Anti-Liberalism”, PGC2018-093573-B-I00 (2019-2022). Agradezco a los árbitros anónimos por sus comentarios para mejorar la versión final. 


\section{Introducción}

Los escritos retóricos de Cicerón De inventione, De oratore, De optimo genere oratorum, Brutus y Orator pueden considerarse obras que muestran un cambio de estilo al abordar las autoridades del pasado que las distinguiría de otras contribuciones del mundo clásico a la retórica y a la oratoria. Presento dos razones que explican este giro argumentativo.

En primer lugar, señalo el hecho de que Cicerón entiende la retórica y la oratoria romanas en el contexto de actos públicos fuertemente ligados a las cortes de justicia en las que la práctica argumentativa de abogados y fiscales era inseparable tanto de las aportaciones de los autores clásicos como de la jurisprudencia anterior. Así, la oratoria, la retórica y la elocuencia son aspectos inseparables del discurso público cuya mejor manifestación histórica fueron las causas judiciales.

En segundo lugar, el consejo ciceroniano de decorum que aparece en sus escritos morales se incluye en De oratore (c. 55 a.e.c.) y en Orator (c. 46 a.e.c.) como sinónimo de lo conveniente o adecuado al discurso, equivalente al término griego prépon (Cicerón 1991, 70, p. 58). El autor habla con frecuencia de decere, de la idea de adaptar los discursos públicos a las circunstancias particulares en que se pronuncian ante distintas audiencias (Cicerón 1991, 73, p. 60). El amplio bagaje de recursos técnicos y argumentativos a disposición del orador en diferentes situaciones sustituye así la adopción de un estilo en particular. Decorum y decere expresan el mismo significado (el segundo es la forma verbal del término). El uso que Cicerón hace de la voz decorum pertenece originalmente a la retórica y pasa luego al ámbito moral convertido en un ideal de comportamiento adecuado (Conde 2009, p. 415).

El sentido de la corrección y de lo apropiado del término decere guardaba así un significado doble. Por un lado, conllevaba un sentido de prestigio moral en el que lo apropiado es ser elocuente ante el auditorio sin renunciar a la filosofía. Las mores, las prácticas y tradiciones romanas comunes a las esferas pública y privada son una guía para asimilar dicho conocimiento en el discurso público. Tanto los exempla históricos como los precedentes legales derivados de la experiencia de los antiguos estaban conectados con un sentido también moralizante que obedecía, por lo tanto, a la mos maiorum (Van der Blom 2010, p. 15). Por otro lado, la idea de decere remite al carácter dúctil de la audiencia. El orador debe aunar a ello la prudentia, entendida como el buen juicio y el conocimiento que se adquiere a través de la experiencia pública y el entrenamiento. Ambos elementos sirven como medios de persuasión que se ajustan a lo conveniente o apropiado. No obstante, 
Cicerón rara vez utiliza en sus obras sobre retórica términos específicos del lenguaje moral o político distintos de los mencionados, sino que basa su argumentación en el examen de las virtudes y defectos de la filosofía y la elocuencia de los modelos del pasado examinándolos uno a uno, a veces de forma sumaria y otras en detalle. Se trata de un rasgo común en las obras de Cicerón sobre retórica.

En concreto, los términos auctoritas, con diferentes declinaciones, y auctor se repiten a lo largo de los trabajos retóricos de Cicerón, y muy en especial en De oratore. Sirven para destacar a las figuras históricas que han contribuido al arte de la oratoria y a la filosofía. Van der Blom encuentra dos razones que llevaron a Cicerón a utilizar autores del pasado: persuadir a la audiencia con su argumentación y hacer ver que él mismo era un conocedor fiable de esos personajes (Van der Blom 2010, p. 8). Estos dos motivos son consistentes con la evidencia disponible. Sin embargo, pueden complementarse con el interés genuino de Cicerón en reivindicar los modelos romanos del pasado para alabar las costumbres de Roma y, al mismo tiempo, educar en un sentido moral a los jóvenes aprendices de retórica y oratoria.

La primera parte de este estudio introduce De inventione con un énfasis en las circunstancias particulares que diferencian esa obra de juventud del resto de los trabajos retóricos de Cicerón. La segunda parte aborda el estilo y contenidos de De oratore y De optimo genere oratorum. La tercera muestra a Brutus y Orator como escritos de vejez que mantienen dos rasgos principales que ya figuraban en sus obras de retórica anteriores: el interés por perfeccionar el aprendizaje de los jóvenes oradores y por incluir enseñanzas que pueden encontrarse tanto en las autoridades del presente como en las del pasado. La última parte ahonda, en primer lugar, en el sentido retórico de proprium como adecuación del latín empleado en el discurso y que aparece en los cuatro trabajos de Cicerón seleccionados; en segundo lugar, trata de exponer la influencia recíproca entre la práctica legal romana en las cortes de justicia y el ars rhetorica como disciplina.

\section{Los modelos del pasado en De inventione}

De inventione (c. 86 a.e.c.) puede considerarse en parte un trabajo innovador. No sólo indaga las distintas fases y procedimientos comunes de rétores y abogados instruidos en retórica, sino también el legado de los autores del pasado en el ars rhetorica. En este sentido, es un manual que acerca los conocimientos generales de la época sobre retórica a los jóvenes alumnos. Sin embargo, en mayor medida también 
demuestra que las contribuciones de las autoridades del pasado deben reconocerse en la elaboración de argumentos. Así, Cicerón afirma que el censor, escritor y líder militar Catón el Viejo (c. 234-149), el también militar y político Cayo Lelio (238-160), el destacado militar Publio Cornelio Escipión (236-183) y los hermanos tribunos de la plebe Tiberio Sempronio Graco (162-133) y Cayo Sempronio Graco (150-121) eran "hombres de gran virtud a los que engrandecía un enorme prestigio y de una elocuencia que era ornato de su virtud y defensa del estado [res publica]" (Cicerón 1997, I, IV.5, p. 90). Para entender las razones de esta admiración por los autores del pasado debe tomarse en cuenta el efecto de las hazañas políticas y militares de Quinto Cecilio Metelo Numídico (160-91). Junto con la escuela estoica liderada por Lucio Elio Estilón (154-74), ambos pueden citarse entre las influencias fundamentales durante su juventud (Kennedy 1972, p. 104).

Para él, los personajes principales del pasado remoto y cercano ofrecen enseñanzas de carácter práctico. Proporcionan una orientación moral para la conducta, que hace inseparables las enseñanzas de la filosofía y de la elocuencia. Su estilo de escritura mezcla referencias del siglo I a.e.c. y, por lo tanto, contemporáneas de Cicerón, con copias literales no identificadas de otros autores. Además, la falta de sistematización de esas referencias es aún más clara cuando se compara $D e$ inventione, un manual de oratoria, con su producción posterior sobre retórica y oratoria. Por ello, la unidad de las obras retóricas ciceronianas se encuentra más en su propósito común para formar jóvenes oradores que en su estilo.

La filosofía aparece como un aspecto fundamental que cualquier orador debe conocer y practicar. El ejercicio de la palabra es así inseparable del conocimiento filosófico, fundamental para proteger a Roma ante sus amenazas internas y externas: "Quien descuida el estudio noble y digno de la filosofía y la moral y consagra todas sus energías al ejercicio de la palabra, se convierte en un ciudadano inútil para sí mismo y perjudicial para su patria" (Cicerón 1997, I, I.2, p. 86).

Con el fin de destacar las contribuciones del pasado, Cicerón menciona a Gorgias de Leontinos (460-380) como "probablemente el más antiguo de los rétores, [que] sostuvo la opinión de que el orador estaba capacitado para hablar con gran elocuencia sobre cualquier tema, atribuyendo así a nuestro arte una materia en mi opinión inmensa y sin límites" (Cicerón 1997, I, V.7, p. 94). Algunas líneas más adelante en De inventione el autor ensalza la habilidad de Hermágoras de Temnos (s. I a.e.c.), quien distinguió los discursos sobre "causas específicas y cuestiones generales" (Cicerón 1997, I, VI.8, p. 95). El argumento que Cicerón 
aduce para enfatizar su intención al escribir y la importancia de estas figuras del pasado tienen que ver con la claridad y la preferencia de la audiencia romana por los asuntos públicos: "Pero como algunos podrían pensar que esta explicación no es suficientemente clara si no incluimos algún ejemplo tomado de una causa política, me parece conveniente dar algún ejemplo de este tipo" (Cicerón 1997, I, XXXIII.55, p. 149).

Si se analiza el estilo de De inventione se observa que la última parte del libro se basa por completo en aspectos propios de las disputas legales. El procedimiento taxonómico que emplea Cicerón cuando menciona los recursos al alcance de cualquier orador consiste en una fórmula para elaborar argumentos en situaciones particulares (Mortensen 2008, p. 35). Cada aspecto de un asunto particular debe considerarse de manera separada para poder alcanzar una imagen general del caso. Tal es la técnica habitual que Cicerón desarrolla en sus diferentes trabajos sobre retórica con dos objetivos: familiarizar a los oradores en formación con las técnicas de personajes del pasado y, en esa misma fase educativa, enseñarles cómo afrontar distintos pleitos legales.

La relevancia para nuestro autor de los asuntos públicos y su conexión con las causas legales es evidente: "En mi opinión, hubo probablemente un tiempo en el que ni las personas sin elocuencia y sabiduría solían dedicarse a los asuntos públicos ni los hombres superiores y elocuentes se ocupaban de causas privadas" (Cicerón 1997, I, III.4, p. 89). El recurso más valioso para aprender el ars rhetorica no consistía sólo en rememorar y alabar a las figuras gloriosas del pasado, sino en ilustrar la autoridad que tradicionalmente los romanos habían exhibido en la vida pública (Goodwin 2001, p. 39). Dicha autoridad descansaba en un conocimiento exhaustivo de las fuentes y una oratoria forense cultivada. Incluso si el orador podía valerse de algunos consejos generales, la forma adecuada de resolver disputas legales no siempre se encuentra en los logros de los antiguos.

El orador ideal para Cicerón es aquel capaz de combinar la elocuencia y la filosofía. A su juicio, la práctica de ambas es un elemento de prestigio público que puede servir para defender las costumbres romanas. El uso elocuente de la palabra ante la multitud es más eficaz cuando el orador manifiesta un conocimiento filosófico (Nederman 2000, p. 252). Para Cicerón, si un orador muestra elocuencia pero carece de conocimientos filosóficos, entonces no podrá alcanzar el modelo ideal descrito; su práctica no puede recomendarse por razones de carácter moral. Si, por el contrario, el orador conoce la filosofía pero ignora las técnicas elocuentes del discurso, su conocimiento carece de valor para la vida pública. 
La preocupación de Cicerón por hacer compatible la originalidad en la composición del discurso con una estricta educación para los oradores jóvenes explica por qué sus trabajos de madurez sobre oratoria son comparativamente más elaborados desde un punto de vista intelectual que sus escritos de juventud (Steel 2001, p. 165). Es más, De inventione, escrito cuando tenía alrededor de 20 años, muestra su ambición por emular a Aristóteles al introducir algunos cambios argumentativos importantes. Por ejemplo, para Cicerón la compilación de observaciones generales que describen episodios y aluden a autores del pasado responde únicamente a los resultados que lograron en vida por medio del uso de la palabra (Dominik y Hall 2010, p. 54). En buena parte de los exempla de carácter histórico que utiliza en sus obras, los personajes aludidos aparecen en grupos de tres con el fin de producir un mejor efecto en la audiencia (Robinson 1986, p. 17).

Desde el punto de vista de la composición, De inventione comparte algunos rasgos con las contribuciones posteriores de Cicerón a la retórica. La primera semejanza tiene que ver con la unión de elocuencia y discurso. La elocuencia sería un rasgo que el orador imprime en el discurso y no algo propiamente del discurso. Cuando el orador ejecuta una intervención pública el resultado puede o no ser elocuente. Si logra serlo, entonces presta un servicio a la res publica. Su contribución pública es valiosa en un sentido cívico y moral en la medida en que dicha elocuencia está ligada al conocimiento de la filosofía y a la experiencia de quienes contribuyeron en el pasado a la vida pública.

El segundo rasgo compartido es la relación entre las disputas legales y la habilidad para razonar en forma correcta a partir de premisas generales. Esto quiere decir que el razonamiento general permite al orador familiarizarse rápidamente con nuevos casos y abordarlos con sus particularidades. En Orator es la habilidad del orador para combinar los estilos vehemente, sencillo e intermedio de acuerdo con las necesidades del decorum lo que determina su elocuencia. Esto significa dotar al discurso de características precisas que lo hagan adecuado para cada audiencia en particular (Picón García 2000, pp. 224-226). Además, debe señalarse que el decorum es una categoría próxima a la de urbanitas en relación con el estilo esmerado del lenguaje y el gusto (Mas 2015, p. 452).

Cicerón entiende de forma eminentemente práctica tanto el ars rhetorica como el conocimiento filosófico, sujetos ambos al servicio público: por una parte, para preservar las costumbres romanas en la vida civil; por otra, para garantizar la estabilidad y el buen orden de la res publica. Ambos fines son inseparables. En De inventione, la guía que 
proporcionan las autoridades del pasado sigue también una orientación práctica:

Cuando quise escribir un tratado de retórica no me propuse imitar un único modelo al cual debería seguir en todos los detalles, con sus cualidades y defectos, sino que, después de reunir todo lo escrito sobre la materia, cogí de cada autor los preceptos que me parecieron más adecuados, eligiendo así lo más sobresaliente de sus diferentes talentos. (Cicerón 1997, II, II.4, p. 198)

\section{La práctica de la oratoria: De optimo genere oratorum y De oratore}

Entre los aspectos generales en De optimo genere oratorum (c. 52 a.e.c.) y De oratore sobresale uno: perseguir la excelencia en la oratoria mediante la adopción de estilos oratorios del pasado. De modo similar a De inventione, en De optimo genere oratorum Cicerón reconoce la finalidad educativa de su trabajo al traducir parte de los discursos de Esquines y Demóstenes. Afirma que esa contribución le sirve para instruir a sus discípulos (Cicerón 2008, IV.13, p. 5). También De oratore basa su contenido en cómo educar a los oradores jóvenes por medio de enseñanzas que no se encuentran en las lecciones de los rétores profesionales, quienes las desconocen (Cicerón 1995, I, XII.52-53, p. 19).

Pueden encontrarse dos aspectos más en De optimo genere oratorum: el itinerario a través de la historia para descubrir hitos del ars rhetorica y la reivindicación de un estilo retórico sui generis. Ambos merecen ser destacados como parte del legado intelectual de los rétores griegos. Demóstenes (Cicerón 2008, II.6, p. 2), Lisias (Cicerón 2008, III.9, p. 3), Tucídides, Isócrates y Platón (Cicerón 2008, V.16-17, pp. 5-6) se mencionan como personajes que contribuyeron ya sea a la invención de argumentos o bien al desarrollo de sistemas de argumentación.

Cuando comenta sobre las habilidades mejores, mediocres y deficientes que un orador entrenado puede poseer, Cicerón enfatiza las diferencias entre Demóstenes (384-322) y Menandro (342-292). Cuando defiende al segundo, argumenta que no quiso emular a Homero en la escritura. Y si Menandro pudo hacerlo así fue porque no era un orador, sino un poeta de un género distinto al de Homero. En cambio, la grandeza de la elocuencia de Demóstenes continúa como un modelo para quien se interese en la práctica de la oratoria. Comparar a Menandro y Homero carece de sentido (Cicerón 2008, II.6, p. 2).

Hacia el final de De optimo genere oratorum Cicerón recupera la disputa entre Demóstenes y Esquines (389-312) con el fin de mostrar por qué es relevante para entender los pleitos legales. Se trata de 
un caso que no obedece a la práctica común de los tribunales de Roma, pero que compara el desempeño público de dos oradores competentes (Cicerón 2008, VII.20-22, p. 7).

La conexión del estilo elocuente que existía fuera de las cortes legales con un sentido de adecuación está lejos de estar claro, más aún porque en el fragmento original en latín no aparece la palabra decorum, sino propriorum: "Nam quoniam eloquentia constat ex verbis et ex sententiis, perficiendum est, ut pure et emendate loquentes, quod est Latine, verborum praetera et propriorum et translatorum elegantiam persequamur" (Cicerón 2008, II.4, p. 2).

La traducción al español es clarificadora: "Pues ya que la elocuencia consta de palabras y de sentencias, ha de lograrse que, los que hablamos con pureza y enmienda, lo cual es en latín, además de que alcancemos la elegancia de las palabras propias y de las trasladadas, persiguiendo su similitud, usemos moderadamente de las ajenas" (Cicerón 2008, II.4, p. 2). Así, los significados de proprium y decorum en la obra retórica de Cicerón están claramente emparentados. Sin embargo, el término proprium señala lo que es propio del latín y adecuado a lo que es costumbre en las audiencias romanas, aunque la importación de palabras extranjeras se admita cuando sea necesario bajo criterios de similitud y adecuación.

Sin embargo, ésta no es la única ocasión en que aparece la idea de adecuación en De optimo genere oratorum. En otro caso, la palabra "inapropiado" se elige como la traducción directa de la expresión non aptum cuando se refiere al uso de un estilo de oratoria que diverge del modelo ático. La palabra se usaría de forma incorrecta si no es apta o apropiada para la circunstancia (Cicerón 2008, II.6-III.8, pp. 2-3). Cicerón defiende el estilo ático como el más apropiado justo en la medida en que evita estos errores comunes en otros estilos de oratoria. La elocuencia es un medio para seleccionar las palabras adecuadas y, aunque es un elemento fundamental del decorum, este término no aparece en el fragmento original latino.

En cambio, a lo largo de De oratore Cicerón opta por evaluar personajes de Grecia y Roma: el cónsul Servio Sulpicio Galba (c. 194-129), el político y militar Marco Antonio (83-30), el constructor griego Hermodoro de Salamina (s. II a.e.c.), el médico Asclepíades de Prusa (c. 12840), el político Marco Licinio Craso (115-53), el filósofo Menedemo de Eretria (c. 345-c. 260), Cármides (s. IV a.e.c.), descendiente de Solón y cuyo nombre funge como título de uno de los diálogos platónicos, y el rétor Apolonio de Alabanda (s. II-s. I a.e.c.), predecesor de Apolonio Molón. En lugar de presentarlos mediante una imagen general, como 
ocurría en De optimo genere oratorum, cada uno de estos personajes se utiliza para ejemplificar distintos comportamientos en los asuntos públicos. Al proceder así, Cicerón plantea una orientación moral específica que se derivaría de cada una de las enseñanzas que él expone.

El interés de Cicerón por reivindicar los modelos de elocuencia romanos frente a los griegos queda patente en este pasaje: "Me darás esta venia, hermano mío, según opino: que anteponga a la de los griegos la autoridad de esos a quienes ha sido por nuestros hombres concedido sumo renombre" (Cicerón 2008, I, VI.23, p. 9). Esta circunstancia no implica que los modelos griegos sean prescindibles o secundarios, como queda claro, por ejemplo, en De finibus bonorum et malorun cuando alaba la claridad y concisión del estilo retórico de Epicuro (Braicovich 2017, p. 146).

Cicerón apela con frecuencia a los mismos personajes por razones distintas y a veces modifica su descripción de acuerdo con cada caso (Robinson 1986, p. 176). Dos razones pueden explicar este cambio. La primera de ellas es que no puede encontrarse un desarrollo sistemático de los contenidos que acerque al lector los estilos de argumentación de los sofistas. La segunda se relaciona con la orientación empírica y subjetiva de la práctica oratoria que sostuvieron los rétores de dicha escuela (Ryan 1983, pp. 310-311). Esta innovación basada en la experiencia que Cicerón introduce desplaza la atención de la teoría a los retos prácticos que afrontaron las autoridades que menciona. No obstante, existe una excepción a esta regla: Partitiones oratoriae (c. 54 a.e.c.) recupera el diálogo como procedimiento argumentativo y pedagógico y omite cualquier referencia a fuentes de autoridad del pasado.

Sin embargo, Cicerón concluye De oratore defendiendo que la oratoria debe restringirse a la competencia técnica en retórica. El contraste entre las autoridades griegas y romanas ofrece el catálogo más extenso de autoridades para reforzar la educación de oradores competentes (Atkins 2000, p. 488). Además, en De oratore la naturaleza humana desempeña un papel fundamental. Cicerón se refiere a ella como naturae humani generis y naturae hominum, con lo que enfatiza el carácter variado de los seres humanos más allá de una misma naturaleza compartida. En la oratoria esta concepción implica atender una amplia variedad de estilos y públicos con el empleo de las técnicas disponibles al orador inteligente y bien entrenado (Gildenhard 2011, p. 61).

La necesidad de una educación general puede aducirse como un factor determinante para recuperar el esquema retórico de Aristóteles, aunque adaptado a la tradición romana. Las referencias explícitas a personajes del pasado son mucho más frecuentes en las obras ciceronianas 
que en la Retórica de Aristóteles por razones obvias de la propia tradición retórica. La única similitud de estilo en el manejo de personajes del pasado tanto en Cicerón como en Aristóteles se limita al fragmento en que el filósofo griego menciona a Hipóloco, probablemente en referencia al hijo de Belerofonte, personaje homérico, y a los tiranicidas Harmodio y Aristogitón (s. VI a.e.c.) (Aristóteles 1998, I, 1368a, p. 114).

Un examen cuidadoso de la Retórica nos permite comprobar el tipo de demostración que utiliza Aristóteles en sus ejemplos y que lo distin-

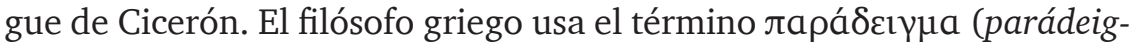
ma) para distinguir procesos de inferencia a partir de un caso particular para demostrar otro particular, pero también para ejemplificar las situaciones que demuestran la validez de un razonamiento (Encinas Reguero 2017, p. 243). En cambio, Cicerón selecciona autoridades del pasado para ensalzar ciertos tipos de comportamientos o modelos ideales sin que ello signifique demostrar la validez de un razonamiento concreto o de otro caso particular. Similitudo, imago y exemplum forman una tríada en la que el exemplum se basa en citar algo que ocurrió en el pasado y el nombre de quien lo llevó a cabo (Leeman 1963, p. 40).

La influencia de Aristóteles en Cicerón se percibe en la idea de discusión deliberativa in utramque partem (Long 1995, pp. 52-53). Se trata de una innovación que encaja en la práctica legal de los abogados versados en retórica y que se recoge en De optimo genere oratorum con el caso de Esquines y Demóstenes: "[Aquella causa judicial con la que Esquines llevó a Ectesifonte] tiene interpretación de leyes suficientemente aguda hacia una y otra parte, y muy grave contienda de méritos hacia la república". Esta traducción respeta el fragmento original en latín: "Habet enim et legum interpretationem satis acutam in utramque partem et meritorum in rem publicam contentionem sane gravem" (Cicerón 2008, VII.20, p. 7).

No obstante, Cicerón contrasta con Aristóteles en su tratamiento de las autoridades del pasado: "La grandeza de alma verdadera y sabia juzga por la honestidad, que es propia especialmente de la naturaleza humana, está puesta en los hechos no en la fama" (Cicerón 2001, I, XIX.64, p. 90). La idea de fama en la Roma de Cicerón señala el estatus de un hombre político en la sociedad (Hellegouarc'h 1972, p. 364). Aristóteles destaca numerosos nombres ilustres que arrojan luz sobre un cierto tipo de razonamiento o costumbre, pero no necesariamente en virtud de sus conocimientos. Puede verse ese procedimiento, por ejemplo, cuando nombra a Ifícrates (s. IV a.e.c.) en el proceso contra Harmodio, pariente del tiranicida del mismo nombre mencionado antes (Aristóteles 1998, II, 1397b, p. 233). 
Uno de los méritos de Cicerón al reconstruir el pasado del ars rhetorica "consiste en relacionar cada medio de persuasión con un estilo de discurso diferente" (Kapust 2011, p. 98). Así pues, es justo reconocer la influencia de Aristóteles sobre Cicerón en la distinción de discursos que aparece en su Retórica (c. 322 a.e.c.). Aunque el filósofo griego cite a múltiples autores en sus textos, no aparece ninguna mención explícita de esos autores como fuentes de autoridad. En cambio, en la introducción a De oratore Cicerón sí habla de estas autoridades de la Antigüedad. Distingue a la oratoria por asentarse sobre reglas consuetudinarias, mientras que otras artes proceden de fuentes remotas (Cicerón 1995, I, III.12, p. 11).

La parte central del pasaje anterior se traduce de forma prácticamente literal: "Reconditis atque abditis e fontibus hauriuntur" (Cicerón 1995, I, III.12, pp. 4-5). Este fragmento muestra la visión de Cicerón de la oratoria a la luz de las contribuciones de su propio tiempo. En consecuencia, las fuentes de autoridad del pasado remoto no son necesariamente un asunto crucial en la formación oratoria. Más aún, la serie de loci (ideas comunes) que de manera repetida aparecen en los escritos ciceronianos están presentes tanto en De inventione como en De oratore. Esos loci se corresponden con las técnicas generales del discurso y estilo que se resumen en las taxonomías retóricas expuestas a lo largo de ambas obras (Mortensen 2008, p. 35).

La precisión técnica es, por lo tanto, un aspecto crucial del análisis histórico de las fuentes de autoridad en De oratore (Fantham 2004, p. 16). Cabe señalar que la circulación de discursos escritos pudo ser un medio para preservar el conocimiento legal, pero constituía una práctica poco corriente hasta apenas una generación anterior a la de Cicerón (Fantham 2004, p. 30). Los tribunales de justicia durante la República romana tardía estaban sometidos tanto a argumentos de carácter extralegal como a reflexiones legales imbuidas de un gran espíritu crítico (Gildenhard 2011, pp. 171).

Este interés por los argumentos extralegales es relevante desde un punto de vista historiográfico para entender, a juicio de Cicerón, qué modelo de formación retórica era más eficaz y apreciado para los abogados. Desde principios del siglo XX se baraja que en la época de Cicerón no era el forum el lugar de celebración preferente de los litigios, sino que era la basilica, a imitación de la práctica común en Grecia, la sede de algunos pleitos. Esta circunstancia redundaría en una mayor afluencia de público a los juicios (Greenidge 1901, p. 133). No obstante, Cicerón menciona el forum como el escenario principal de las discusiones públicas. Si este dato se toma en cuenta, entonces la relación entre las 
discusiones legales y las técnicas retóricas propias de los trabajos de Cicerón nos ofrecen la imagen general de un nuevo movimiento favorable a la retórica legal romana sobre las discusiones filosóficas desconectadas de la práctica pública. En cualquier caso, esta corriente supuso la reivindicación del conocimiento legal de Roma sobre las leyes prescritas por los griegos. Un pasaje en De oratore lo ejemplifica al afirmar que las leyes de Roma superan a las de otros pueblos, incluso a las griegas (Cicerón 1995, I, XLIV.197, p. 67).

\section{El oficio de orador descrito en Brutus y Orator}

Orator reivindica las disputas legales en las cortes de Roma. Entre algunos de los casos que Cicerón cita encontramos En defensa de Ctesifonte de Demóstenes (Cicerón 1991, 26, p. 38; Cicerón 1991, 111, p. 75; Cicerón 1991, 133, p. 86), Pro Caecina, Pro Rabirio, los sietes discursos de Accusatio — que probablemente se identifique con Verrinas-, Pro Cluentio y Pro Cornelio (Cicerón 1991, 103, p. 72). De nuevo Pro Cornelio (Cicerón 1991, 108, p. 74), Accusatio (Cicerón 1991, 131, p. 85) (Cicerón 1991, 210; Cicerón 1991, 131) y otra vez Pro Cornelio (Cicerón 1991, 232, pp. 143-144). Cada uno de estos casos pone de manifiesto el oficio de abogado como una figura clave en la retórica de la Antigua Roma al introducir una clara orientación práctica de la oratoria casi ausente entre los griegos.

De forma similar, Orator defiende el estudio de cualquier autor digno de elogio incluso si sus obras son de menor calidad que las de otros (Cicerón 1991, 5, pp. 28-29). Esto puede interpretarse como la principal razón de Cicerón para incluir figuras menores en sus escritos. Además, es el primer autor conocido en mencionar en su obra a César, Craso y Pompeyo como autoridades históricas (Van der Blom 2010, p. 77).

La colección de autores de Cicerón sirve de manera explícita a un fin educativo y moral, a saber, mejorar el conocimiento de sus alumnos sobre una amplia lista de fuentes y casos legales, así como perfeccionar su conocimiento moral. Según el propio Cicerón, esta tarea concierne tanto a los más excelentes como a los que no lo son:

Y si a alguien le falta por su naturaleza esa fuerza propia de una gran inteligencia o está menos instruido en las técnicas de las artes superiores, que siga sin embargo el camino que pueda, ya que para el que persigue el primer puesto es honroso quedar en segundo o tercer lugar. (Cicerón 1991, 4, p. 28) 
Cicerón elabora en Orator una guía de perfeccionamiento legal que pretende incorporar el conocimiento filosófico a la elocuencia propia de la oratoria. No trata de inventar o redefinir el significado de los términos de la filosofía o la oratoria, sino que trata de hacer ver tanto el valor formativo como el puramente práctico de la unión entre filosofía y elocuencia. Para ello no duda en criticar a los filósofos anteriores que habían negado la combinación de estas enseñanzas:

De esta forma, nuestra elocuencia forense, despreciada y rechazada por los filósofos, ha carecido sin duda de esa importante ayuda [de la filosofía], pero, gracias a los adornos de las figuras de palabra y de pensamiento, ha tenido éxito ante el pueblo y no ha tenido miedo de la opinión y crítica de unos pocos. De esta forma, a los cultos les faltó la elocuencia popular, y a los oradores el refinamiento de la cultura. (Cicerón 1991, 13, pp. 31-32)

Así, la tarea de Cicerón consiste en arrojar luz sobre las virtudes y habilidades de esos maestros también en el manejo de los asuntos públicos, incluso si proceden del pasado reciente y no son los más excelentes en su arte. Él mismo confiesa que la petición de su amigo Bruto le ha llevado a escribir Orator justo en una época en la que considera la virtud como una excepción: "He emprendido esta obra inmediatamente después de haber terminado el Catón, obra que nunca habría intentado escribir por temor a estos tiempos contrarios a la virtud, si no hubiese considerado que era sacrílego no hacer caso a tus ruegos" (Cicerón 1991, 35, p. 42).

Es razonable pensar que las ideas estoicas contemporáneas de Cicerón lo llevan a concebir la eloquentia y la sapientia en el marco de una teoría nueva de la retórica: un paso más allá de la mera repetición de los trabajos griegos sobre la disciplina (Inabinet 2011, p. 15). En este punto resulta pertinente recuperar las observaciones de James May sobre la preferencia de Cicerón por los oradores capaces de adaptarse a diferentes situaciones. Para May los sistemas retóricos codificados en manuales siglos atrás por los griegos se convirtieron en principios obligados para los oradores en formación. Durante la juventud de Cicerón esto ya era una práctica común entre los alumnos romanos de oratoria (May 2002, p. 51).

También en Brutus (c. 46 a.e.c.), al igual que en De officiis, Cicerón menciona la fama como un aspecto accesorio, desprovisto de importancia si no se acompaña de valía personal: "Destacó Quinto Pompeyo por su nada despreciable elocuencia, alcanzando las más altas magistraturas en reconocimiento a su propia valía y no por la fama de sus antepasados" (Cicerón 2000, 96-97, pp. 95-96). La elocuencia es fun- 
damental para ascender socialmente y prestar servicios a la res publica por encima del buen linaje. Así, esta cualidad aparece como uno de los principales rasgos del discurso público y el entrenamiento retórico de los abogados pasa a ser esencial en Roma. Sin embargo, Cicerón considera que las enseñanzas de los filósofos están por encima de las de los rétores de su tiempo:

Entiendo que dé muchas veces la impresión de estar diciendo cosas nuevas, cuando en realidad estoy diciendo cosas muy viejas, pero que la mayoría no ha oído; y confieso que soy un orador — si es que lo soy, o en la medida en que lo sea- salido, no de los talleres de los rétores, sino de los paseos de la Academia. (Cicerón 1991, 12, p. 31)

A pesar de la orientación legal que Cicerón confiere a la filosofía, reconoce el conocimiento filosófico como una fuente más provechosa desde el punto de vista del aprendizaje, en los sentidos técnico y moral, que la que ofrecen los maestros de oratoria: "Sin una formación filosófica no podemos distinguir el género y la especie de ninguna cosa, ni definirla, ni clasificarla, ni juzgar lo que es verdadero y lo que es falso, ni analizar las consecuencias lógicas, ver lo contradictorio y distinguir lo ambiguo" (Cicerón 1991, 16, pp. 32-33).

Sin embargo, Cicerón destaca que cualquiera puede figurarse en la mente pensamientos que trascienden la existencia temporal (Long 1995, pp. 48-49). Si esta creencia se traduce al ámbito de la retórica significa que las ideas platónicas, que según Cicerón constituyen los modelos provistos por las fuentes antiguas, pueden aplicarse al oficio del orador. Este objetivo pedagógico presenta la filosofía como un arte compatible con la retórica y no como su opuesto, lo que encaja en tres formas de exponer las ideas abstractas ante la audiencia. Exempla (ejemplos), imago (símil) y conlatio (paralelismo) son precisamente las tres modalidades de refuerzo del argumento que prefiere Cicerón (Van der Blom 2010, pp. 66-67).

El tipo de auctoritates que Cicerón preconiza se asienta tanto en el pasado como en el presente. La civilización romana aporta a la oratoria una concepción de pensamiento práctico que une a la filosofía y a la retórica a través de las lecciones que enseñan tanto las fuentes antiguas como la práctica legal. Cicerón no separa el objetivo educativo de la retórica del conocimiento de la práctica real en los asuntos públicos. El tipo de responsabilidad cívica por la res publica que Cicerón recupera no puede abordarse sin la ayuda del pasado reciente o del pasado remoto. Se trata de una consideración de los personajes pretéritos como auctoritates identificadas como fuentes, tanto intelectuales como morales. 
Como muestra, en Brutus Cicerón señala con nitidez su preferencia por preservar los modelos romanos de elocuencia. Este pasaje lo ilustra: "Pero la ignorancia de nuestros oradores es tal que, deleitándose con la antigua sencillez de los griegos que llaman ática, no saben apreciarla en Catón. Quieren ser otros Hipérides y otros Lisias. iEstupendo! ¿Pero por qué no otros Catones?" (Cicerón 2000, 67-68, p. 83).

Asimismo, en Brutus se demuestra la gran utilidad que Cicerón encuentra en el aprendizaje de la filosofía aplicada a la oratoria. En su diálogo con Bruto se dirige a él en los siguientes términos: "Tu tío materno, como sabes, ha tomado de los estoicos lo que tenía que tomar, pero ha aprendido a hablar siguiendo el método y la instrucción de los maestros de retórica. Pues si hubiera que tomar todo de los filósofos se forjaría mejor el discurso siguiendo las enseñanzas de los peripatéticos" (Cicerón 2000, 119, p. 106).

Al mencionar a Quinto Hortensio hacia el final de Brutus Cicerón deja patente que la enseñanza de principios, y no la enumeración de oradores, es el objetivo de su exposición: "Pero, como toda esta conversación nuestra no pretende ser una simple enumeración de oradores, sino también establecer algunos preceptos, puedo exponer brevemente las faltas que merecen, por así decir, ser anotadas y criticadas en Hortensio" (Cicerón 2000, 319, p. 192).

En el penúltimo pasaje de la obra está claro que Cicerón anima a Bruto a mejorar la oratoria y el ejercicio de la abogacía frente a la mayoría de los oradores. Para ello le aconseja distinguirse de los demás tomando en cuenta las enseñanzas de la filosofía:

Y es que no es justo que tú, equipado con las más fecundas disciplinas -que, como no podías beberlas en la patria, tuviste que ir a buscarlas a la ciudad que siempre ha sido considerada como la morada del saber-, entres a formar parte de la masa de abogados. ¿Para qué, entonces, te adiestró Pamenes, el hombre, con mucho, más elocuente de Grecia? ¿Para qué las enseñanzas de la Antigua Academia y de su heredero Aristo, mi huésped y amigo, si luego vamos a ser iguales a la mayor parte de los oradores? (Cicerón 2000, 332, p. 198).

El giro de Cicerón hacia los autores del pasado implica un supuesto epistemológico: esas autoridades proporcionan un conocimiento práctico sin el que la formación de los oradores está incompleta. Los escritos de Cicerón alaban a esas fuentes de autoridad. En sus obras retóricas es difícil atribuirle una mención de sí mismo en ese sentido, algo que no ocurre en sus trabajos legales, como en Pro Sulla. Puede pensarse, de manera muy razonable, que trató de ofrecer al lector una visión com- 
parativa de las aportaciones de distintas figuras de la vida pública en lugar de destacar sus propios méritos para no abusar de su posición de autoridad (Goodwin 2001, p. 49).

\section{El sentido de adecuación ciceroniano}

En las líneas anteriores reivindiqué la defensa de Cicerón de las habilidades prácticas de las que gozaban las autoridades del pasado como un paso innovador para la enseñanza escrita de la retórica y de la oratoria. Expuse dos argumentos a favor de esta tesis. El primero de ellos afirma que los tribunales de justicia de Roma condicionaron la atención especial que Cicerón dedica a las cuestiones prácticas. Para nuestro autor, las autoridades procedentes de la Antigua Roma encarnaban una visión distintiva de la retórica en comparación con las aportaciones griegas. El segundo argumento enfatiza la adaptación del discurso público en el sentido de lo apropiado. Las circunstancias que presenta a través de discursos y hechos históricos exponen diferentes formas de adaptar los conocimientos de retórica antigua a los casos del presente de Cicerón. Dicho conocimiento refuerza la autoridad tanto técnica como moral del orador ante la audiencia y, al mismo tiempo, permite trazar estrategias previas en los casos legales basadas en la memorización de los discursos de dichos personajes y de sucesos históricos.

El sentido ciceroniano de la prudentia significa buen juicio, un tipo de sabiduría práctica de la que el orador debe disponer y que guarda una relación estrecha con el sentido de adaptación o adecuación del discurso: "En todo tiempo, el gusto del auditorio ha sido la medida orientadora de la elocuencia de los oradores. Efectivamente, todos los que buscan la aprobación tienen en cuenta los gustos de los oyentes y se pliegan y acomodan a ellos, a su arbitrio y sus gestos" (Cicerón 1991, 24, pp. 37-38).

Cicerón procede en primer lugar con el establecimiento de las fuentes básicas del saber a fin de adaptar de un modo razonable las enseñanzas de los antiguos a los requerimientos del presente. Así pues, puede decirse que, en este sentido, Cicerón origina una nueva tradición de literatura académica sobre el ars rhetorica que une las enseñanzas de los griegos con las hazañas de Roma al considerar la contención en el comportamiento público como un elemento genuinamente romano. A través de la caracterización ciceroniana de proprium, el término se liga claramente con lo apropiado, con la contención y con la verdad: "Me parece que estoy en la plenitud de mi derecho, si me atribuyo lo que es propio del orador, hablar con propiedad, con claridad y con elegancia, 
ya que tras de ese logro he consumido las horas de mi vida" (Cicerón 2001, 2, p. 58).

\section{Cicerón y la tradición de la retórica romana}

Incluso si consideramos los escritos retóricos de Cicerón como el resultado de la tradición republicana romana, no es erróneo pensar que, desde un punto de vista argumentativo y de acuerdo con sus contenidos, trata de preservar la base helénica del conocimiento. Cicerón no es sólo el fundador de una retórica genuinamente romana, sino un defensor de la superioridad de ciertos rasgos del carácter que él consideraba también genuinamente romanos.

Thomas Habinek y Alessandro Schiesano defienden que las principales cualidades romanas como gravitas, constantia o magnitude animi ya eran estimadas entre los griegos más sobresalientes. De acuerdo con Cicerón, los romanos sólo pueden imitar estas virtudes en la medida en que dependen de la natura. Es en doctrina donde el genio griego puede ser sobrepasado por los romanos (Habinek y Schiesano 1997, p. 8). Junto a ella, la constantia es una cualidad esencial. El significado de guía moral y principio filosófico del término constantia ocupan un lugar especialmente significativo en sus Cartas a Ático (Tracy 2012, p. 80).

No está fuera de lugar pensar que el hecho de que se hayan conservado la mayoría de sus escritos es clave para entender la relevancia histórica de Cicerón. Baste comentar el ejemplo de Quintiliano, quien lo cita 689 veces en su Institutio oratoria (Van Deusen 2013, p. 48). El principio de imitatio fue completamente adoptado por Quintiliano como un medio para la formación retórica en la tradición escrita (Logie 2003, p. 359). Aunque se inspire en la figura de Cicerón en su obra, como se desprende del número de citas y de muchos de sus contenidos, ello no obsta para que censure en el libro IX de su Institutio oratoria las imprecisiones y equívocos que encuentra en la retórica ciceroniana (Pérez Castro 2000, p. 49). La inspiración de Quintiliano en la autoridad original se basa en una forma muy peculiar de entender la contribución de sus predecesores, a quienes reconoce en forma explícita como fuentes de conocimiento (Logie 2003, pp. 361-63).

Es posible establecer algunas pautas de estilo que llevan a pensar que los oradores contemporáneos de Cicerón tuvieron una influencia decisiva en sus primeros escritos. Su preferencia por el uso de palabras latinas al sustituir las palabras técnicas griegas por alternativas latinas de uso frecuente es un rasgo común de sus obras (Von Albrecht 2003, pp. 46-47). Su empleo consciente de los exempla de la tradición roma- 
na apunta a que los consideraba útiles ya sea desde un punto de vista retórico o bien como guías de la conducta (Van der Blom 2010, p. 19).

Resulta relevante que Cicerón se decantase desde muy temprano por prestigiar el latín sobre el griego como ejemplo de su interés por reforzar la mos maiorum romana, lo que pone en relación el interés ciceroniano por preservar las costumbres romanas con la consecución moral del decorum. Es de suponerse que una corriente política afín a los ideales de la República romana influyera en una audiencia dispuesta a acoger un discurso favorable a la recuperación de las mores que típicamente se identificaban como romanas. Esto es consistente con el significado de lo justo (ius) para Cicerón, y que expresa a través de dos elementos: la mos maiorum y las leges (Greenidge 1901, p. 80).

Por una parte, en las cortes judiciales romanas en la época de Cicerón la distinción entre juristas y abogados era nítida, e incluso se entendía que ambos oficios se contraponían entre sí. Cicerón manifiesta que precisamente un ejercicio retórico de los abogados consiste en acusar a otros abogados de ser juristas para, de ese modo, desprestigiarlos en el curso de un litigio (Wibier 2018, p. 101). Por otra parte, el entrenamiento en retórica y oratoria es justo uno de los aspectos insustituibles en la formación de abogados, que en la práctica eran oradores profesionales con conocimiento de las leyes y de la jurisprudencia. Por lo tanto, las tensiones entre la formación y práctica argumentativa de juristas y abogados son evidentes en el periodo de la República romana tardía. Como ejemplo cabe señalar la indicación expresa de los casos que constantemente aparecen en De inventione. Éstos se describen en clave de retórica judicial mediante la oposición de la labor persuasiva de los abogados a la interpretación de las leyes que corresponde a jueces y a su aprobación, tarea de los legisladores (Cicerón 1997, I, LXX.39, p. 159).

\section{Observaciones finales}

A lo largo de este trabajo argumenté en favor de reconocer que los escritos retóricos de Cicerón son una innovación histórica mayor en el uso de las autoridades del pasado. Su aportación consiste en considerar a figuras históricas como relevantes en la medida en que lograron resultados prácticos que pueden aplicarse a la retórica romana tardorrepublicana basada en las disputas públicas de carácter legal, más aún si se tiene en cuenta que no fue hasta aproximadamente entre los años 85 y 82 a.e.c. que aparece la primera obra retórica romana escrita en prosa, Rhetorica ad Herennium, atribuida inicialmente a Cicerón y que hoy, con la evidencia disponible, puede atribuirse con razonabilidad a Cornificio (Farias 2002, p. 224). 
Introduje dos argumentos en defensa de esta innovación argumentativa de Cicerón. El primero tiene que ver con la idea detrás de los términos proprium y decere como la adaptación apropiada, en un sentido técnico y moral, del discurso a las circunstancias particulares del caso. El segundo argumento destaca la práctica común en las cortes de justicia romanas como la base de los fundamentos retóricos de los que Cicerón habla en sus escritos junto a las múltiples menciones que hace de la unión de la filosofía y la elocuencia en sus obras sobre retórica. A través de estas consideraciones, la oratoria se reivindica como un bien público que hace posible la combinación de servicio civil, la presentación canónica del discurso y el saber sujeto a los fines educativos.

$\mathrm{Al}$ examinar estos cinco escritos sobre oratoria, a saber, De inventione, De optimo genere oratorum, De oratore, Brutus y Orator, mi análisis se basó tanto en sus rasgos de estilo comunes (la finalidad educativa de la oratoria, el uso de modelos basados en personajes del pasado y el vocabulario compartido) como en su diferente cronología, la cual abarca tres periodos de la vida de Cicerón: De inventione (juventud), De oratore (madurez) y De optimo genere oratorum junto a Brutus y Orator (vejez). Mientras que De inventione y De optimo genere oratorum incluyen una gran cantidad de referencias a las autoridades de la retórica, De oratore y, sobre todo, Orator, ofrecen una amplia presentación de cuestiones de retórica desde la perspectiva de las disputas legales. No obstante, estos cuatro escritos comparten una consideración común de las autoridades del pasado por su contribución al ámbito público. Cicerón trata de mostrar cómo sólo los asuntos de la vida política pueden unir el saber de la Antigüedad con los fines educativos y con las exigencias propias de las circunstancias de Roma.

\section{REFERENCIAS BIBLIOGRÁFICAS}

\section{Fuentes primarias}

Aristóteles, 1998, Retórica, trad. A. Bernabé, Alianza, Madrid.

Cicerón, Marco Tulio, 1991, El orador, trad. E. Sánchez Salor, Alianza, Madrid. Cicerón, Marco Tulio, 1995, Acerca del orador, trad. A. Gaos Schmidt, UNAM, México.

Cicerón, Marco Tulio, 1997, La invención retórica, trad. S. Núñez, Gredos, Madrid.

Cicerón, Marco Tulio, 2000, Bruto, trad. M. Mañas Núñez, Alianza, Madrid.

Cicerón, Marco Tulio, 2001, Sobre los deberes, trad. J. Guillén, Alianza, Madrid. Cicerón, Marco Tulio, 2008, Del óptimo género de los oradores, trad. B. Reyes Coria, UNAM, México. 


\section{Fuentes secundarias}

Atkins, Margaret, 2000, "Cicero", en Christopher Rowe y Malcolm Schofield (comps.), The Cambridge History of Greek and Roman Political Thought, Cambridge University Press, Cambridge.

Braicovich, Rodrigo, 2017, "Racionalismo y retórica en Filodemo de Gadara”, Diánoia, vol. 62, no. 79, pp. 141-164, <https://doi.org/10.22201/ iifs.18704913e.2017.79>.

Conde, Juan Luis, 2009, "El discurso deliberativo y la voz de la conciencia", en Trinidad Arcos, Jorge Fernández López y Francisca Moya del Baño (comps.), 'Pectora Mulcet'. Estudios de retórica y oratoria latinas (I), Instituto de Estudios Riojanos, Logroño.

Dominik, William y Jon Hall (comps.), 2010, A Companion to Roman Rhetoric, Wiley-Blackwell, Oxford.

Encinas Reguero, $\mathrm{M}^{\mathrm{a}}$. Carmen, 2017, "El ejemplo y la semejanza en la Retórica de Aristóteles", Emerita. Revista de Lingüística y Filología Clásica, vol. 85, no. 2, pp. 241-260, <https://doi.org/10.3989/emerita.2017.v85.i2>.

Fantham, Elaine, 2004, The Roman World of Cicero's De Oratore, Oxford University Press, Oxford.

Farias, Pedro, 2002, "Reflexiones sobre Cicerón. Las paradojas. El regreso a Cicerón", Revista de Estudios Políticos, no. 117, pp. 221-234.

Gildenhard, Ingo, 2011, Creative Eloquence. The Construction of Reality in Cicero's Speeches, Clarendon Press, Oxford.

Goodwin, Jean, 2001, "Cicero's Authority", Philosophy and Rhetoric, vol. 34, no. 1, pp. 38-60, <https://doi.org/10.1353/par.2001.0003>.

Habinek, Thomas y Alessandro Schiesano, 1997, The Roman Cultural Revolution, Cambridge University Press, Cambridge.

Hellegouarc'h, Joseph, 1972, "Les recompenses dues a l'homme politique et la notion de célébrité Gloria-Honos-Dignitas", en Le vocabulaire latin des relations et des partis politiques sous la Republique, Les Belles Lettres, París.

Greenidge, Abel Hendy Jones, 1901, "The Courts of the Ciceronian Period", en Abel Hendy Jones Greenidge, The Legal Procedure of Cicero's Time, Clarendon Press, Oxford.

Inabinet, Brandon, 2011, “The Stoicism of the Ideal Orator. Cicero's Hellenistic Ideal", Advances in the History of Rhetoric, no. 14, pp. 14-32, < https://doi. org/10.1080/15362426.2011.559400>.

Kapust, Daniel, 2011, "Cicero on Decorum and the Morality of Rhetoric", European Journal of Political Theory, vol. 10, no. 1, pp. 92-112, < https://doi. org/10.1177/1474885110386007>.

Kennedy, George, 1972, The Art of Rhetoric in the Roman World, Princeton University Press, Princeton.

Leeman, Anton Daniël, 1963, "Rhetoric in the Archaic Period", en Orationis Ratio. The Stylistic Theories and Practices of the Roman Orators, Historians, and Philosophers, Adolf M. Hakkert, Ámsterdam, pp. 19-42. 
Logie, John, 2003, “'I Have no Predecessor to Guide My Steps': Quintilian and Roman Authorship", Rhetoric Review, vol. 22, no. 4, pp. 353-373, <https:// doi.org/10.1207/S15327981RR2204_2>.

Long, Anthony Arthur, 1995, "Cicero's Plato and Aristotle", en Jonathan Powell (comp.), Cicero the Philosopher, Clarendon Press, Oxford.

Mas, Salvador, 2015, "Verecundia, risa y decoro: Cicerón y el arte de insultar", Isegoría. Revista de Filosofía Moral y Política, no. 53, pp. 445-473, <https:// doi.org/10.3989/isegoria.2015.053.01>.

May, James M., 2002, Brill's Companion to Cicero. Oratory and Rhetoric, Brill, Boston.

Mortensen, Daniel E., 2008, "The Loci of Cicero", Rhetorica. A Journal of History of Rhetoric, vol. 26, no. 1, pp. 31-56, <https://doi.org/10.1525/ rh.2008.26.1.31>.

Nederman, Cary J., 2000, "Rhetoric, Reason, and Republic: Republicanisms Ancient, Medieval and Modern", en James Hankins (comp.), Renaissance Civic Humanism, Cambridge University Press, Cambridge.

Pérez Castro, Lois C., 2000, "Quintiliano y la autoridad de Cicerón: acerca del Libro IX de la Institutio oratoria", Emerita. Revista de Lingüística y Filología Clásica, vol. 68, no. 1, pp. 47-51, <https://doi.org/10.3989/emerita.2000. v68.i1.158>.

Picón García, Vicente, 2000, "De Cicerón a Quintiliano: retórica de los estilos y doctrina de la escritura", Edad de Oro, vol. 19, pp. 223-238, <https://doi. org/10.15366/edadoro2000.19>.

Robinson, Arthur Wirt, 1986, Cicero's Use of People as Exempla in his Speeches, Indiana University Press, Bloomington.

Ryan, George, 1983, Ratio et Oratio. Cicero, Rhetoric, Princeton University Press, Princeton.

Steel, Catherine Elizabeth, 2001, Cicero, Rhetoric, and Empire, Oxford University Press, Oxford.

Tracy, Catherine, 2012, "Cicero's Constantia in Theory and Practice", en Walter Nicgorski (comp.), Cicero's Practical Philosophy, University of Notre Dame Press, Notre Dame.

Van der Blom, Henriette, 2010, Cicero's Role Models. The Political Strategy of a Newcomer, Oxford University Press, Oxford.

Van Deusen, Nancy (comp.), 2013, Cicero Refused to Die. Ciceronian Influence Through the Centuries, Brill, Boston.

Von Albrecht, Michael, 2003, Cicero's Style. A Synopsis, Brill, Leiden.

Wibier, Matthijs, 2018, "Cicero's Reception in the Juristic Tradition of the Early Empire”, en Paul J. Du Plessis (comp.), Cicero's Law. Rethinking Roman Law of the Late Republic, Edinburgh University Press, Edimburgo.

Recibido el 7 de julio de 2020; revisado el 2 de diciembre de 2020; aceptado el 3 de marzo de 2021. 